\title{
Modified single-balloon endoscopy for ERCP in a patient with Billroth II gastrectomy
}

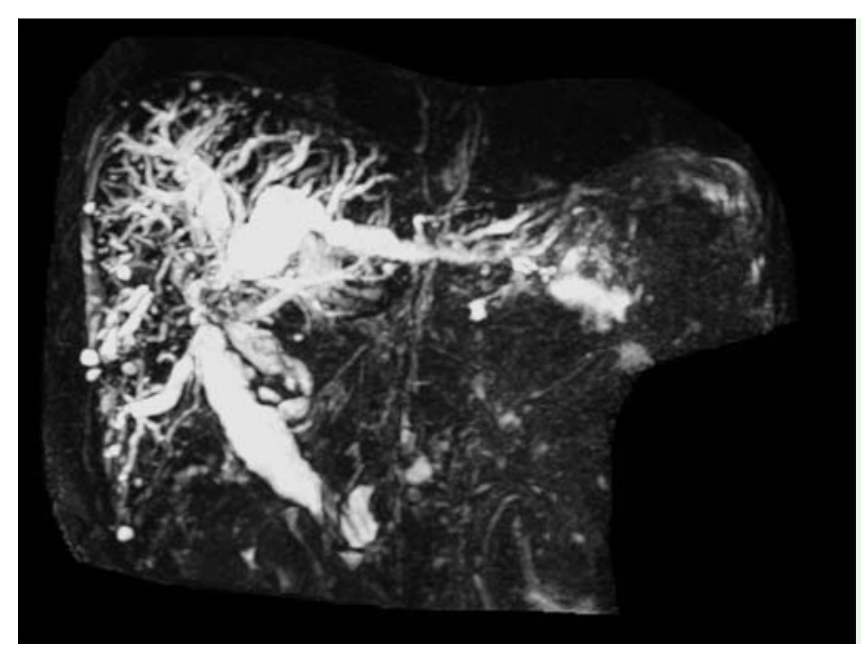

Fig. 1 Magnetic resonance cholangiopancreatography (MRCP) in an 84-year-old man with a history of hepatocellular carcinoma showing a tumor invading the bifurcation of common bile duct.

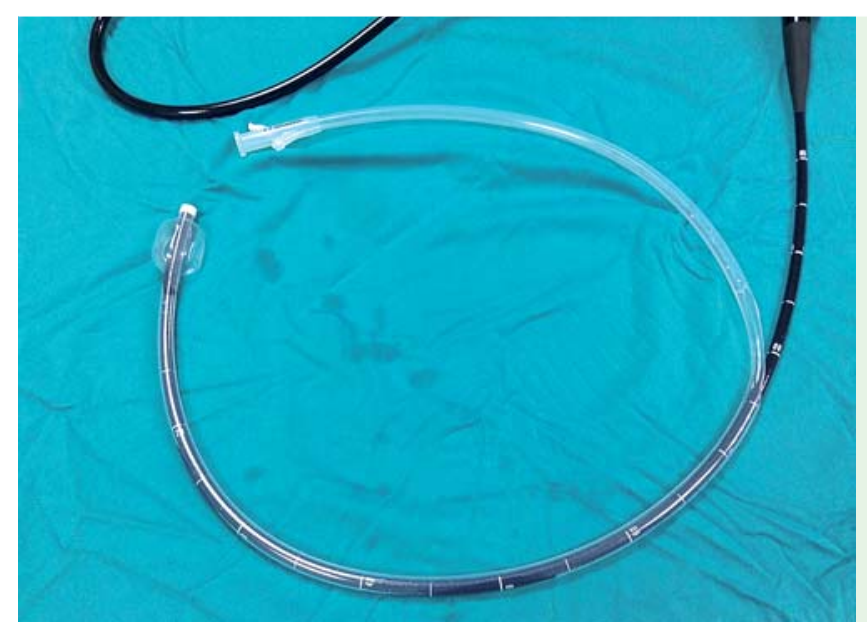

Fig. 2 Photograph of the overtube with an aperture at a point $75 \mathrm{~cm}$ from its tip on the side opposite to the pressure line with a conventional forwardviewing upper gastrointestinal endoscope inserted through it via the aperture.

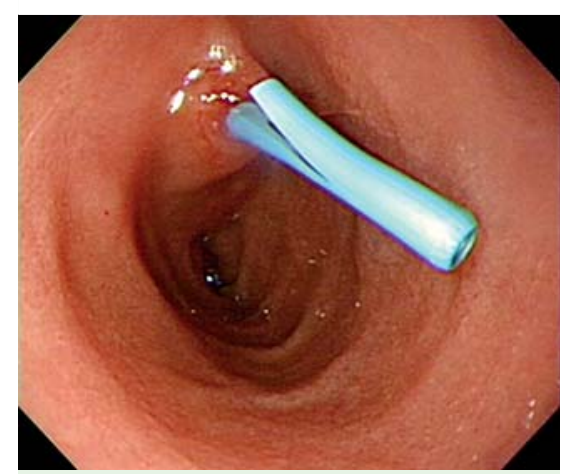

Fig. 3 Image during the modified single-balloon enteroscopy-assisted endoscopic retrograde cholangiopancreatography (ERCP) procedure showing a plastic stent that has been successfully placed after location of the papilla via the afferent loop.
An 84-year-old man with a history of hepatocellular carcinoma treated by transcatheter arterial chemoembolization and percutaneous ethanol injection therapy 2 years previously was admitted with jaundice. Magnetic resonance cholangiopancreatography (MRCP) showed a tumor invading the bifurcation of the common bile duct with bilateral intrahepatic duct dilatation ( $\bullet$ Fig.1). Endoscopic retrograde cholangiopancreatography (ERCP) was considered but as the patient had undergone a previous Billroth II gastrectomy and was concerned about possible complications, we held back from performing this procedure.
A modified single-balloon enteroscopyassisted ERCP was planned instead, using a sliding tube with a balloon (XST-SB1; Olympus) and a balloon controller (XMAJ1725; Olympus). The sliding tube has a working length of $132 \mathrm{~cm}$, with outer and inner diameters of $13.2 \mathrm{~mm}$ and $11 \mathrm{~mm}$ respectively, and has a silicone balloon at its tip [1]. An adequate aperture was made in the overtube at a point $75 \mathrm{~cm}$ from its tip on the side opposite to the pressure line. A conventional forward-viewing upper gastrointestinal endoscope with this modified single balloon was used to perform ERCP by the standard single-balloon method ( Fig.2). The papilla was found via the afferent loop and a plastic stent was successfully placed with no complications (๑ Fig.3 and $\bullet$ Fig.4).

It is usually difficult to perform ERCP in postoperative patients because of their altered anatomy. Balloon-assisted enteroscopy, with either a double or single balloon, can be used for these patients $[1,2]$. Although single-balloon enteroscopy-assisted ERCP is an accepted method, some endoscopists believe that "short-type" double-balloon enteroscopy is more effective in such patients [3]. In one multicenter experience of overtube-assisted enteroscopic ERCP in patients with surgically altered pancreaticobiliary anatomy, the overall success rates were $60 \%$ and $63 \%$ in single-balloon and double-balloon procedures respectively. There was no significant difference between ERCPs performed by single-balloon or double-balloon enteroscopy [4].

There are many published case reports using double-balloon enteroscopy for ERCP in patients with altered anatomy, but reports of single-balloon enteroscopyassisted ERCPs are rare $[1,5,6]$. One reason for this is that double-balloon enteroscopy was developed before single-balloon enteroscopy. The other reason is that "short" double-balloon enteroscopy is easy to use for ERCP in patients with altered anatomy. Single-balloon enteroscopy has a $200-\mathrm{cm}$ working length and the accessories are very limited [7].

Itoi et al. developed one possible method for single-balloon enteroscopy-assisted ERCP [1]. They performed traditional single-balloon enteroscopy first; they then made an aperture in the overtube at a point $100 \mathrm{~cm}$ from its tip. A conventional forward-viewing upper gastrointestinal endoscope was then substituted for the 


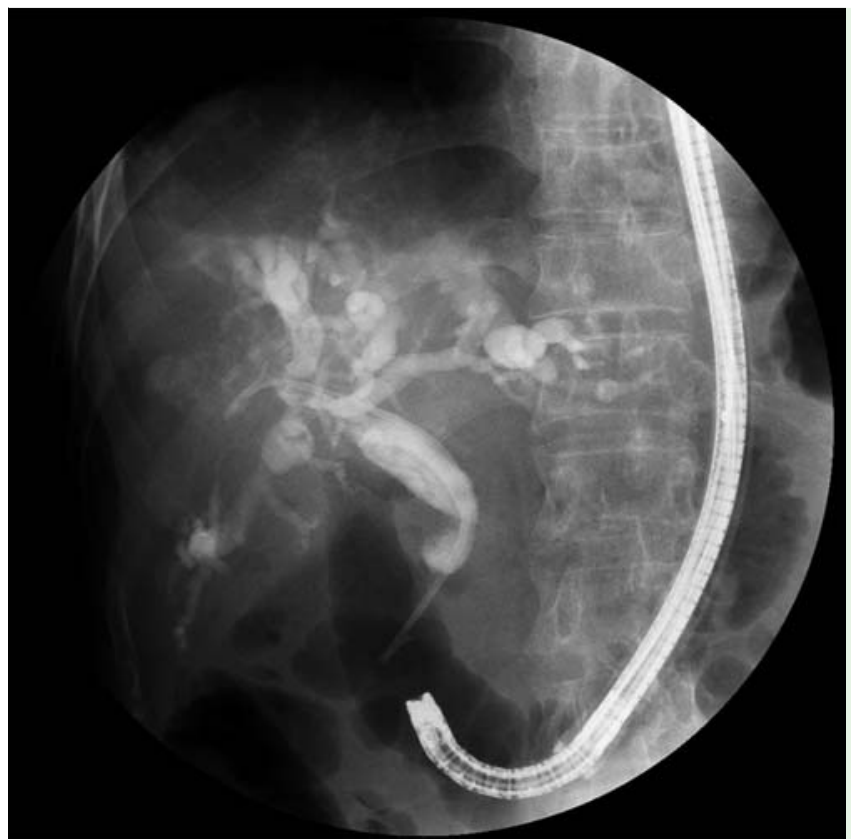

enteroscope before the ERCP. Their overall success rate for therapeutic ERCP was $76.9 \%$; however, this is a complicated method.

Here, we report an easier method that we have developed for ERCP in patients with altered anatomy. We make an aperture in the overtube at a point $75 \mathrm{~cm}$ from its tip, which enables us to complete the balloon-assisted ERCP with a conventional forward-viewing upper gastrointestinal endoscope - the enteroscopy is unnecessary in our method. The one limitation to our method is that it is not suitable for patients with a Roux-en-Y anastomosis because the loop from the anastomosis to the papilla is longer in this situation than after other types of surgery.

Endoscopy_UCTN_Code_TTT_1AR_2AK

Competing interests: None
Fig. 4 Radiographic image during the modified single-balloon enteroscopy-assisted endoscopic retrograde cholangiopancreatography (ERCP) showing the correctly positioned plastic stent.

\section{References}

1 Itoi $T$, Ishii $K$, Sofuni A et al. Single-balloon enteroscopy-assisted ERCP in patients with Billroth II gastrectomy or Roux-en-Y anastomosis (with video). Am J Gastroenterol 2010; 105: $93-99$

2 Koornstra JJ, Fry L, Monkemuller K. ERCP with the balloon-assisted enteroscopy technique: a systematic review. Dig Dis 2008; 26: $324-329$

3 Matsushita M, Shimatani M, Ikeura T et al. "Short" double-balloon or single-balloon enteroscope for ERCP in patients with Billroth II gastrectomy or Roux-en-Y anastomosis. Am J Gastroenterol 2010; 105: 2294; author reply 2294-2295

4 Shah RJ, Smolkin M, Yen $R$ et al. A multicenter, U.S. experience of single-balloon, double-balloon, and rotational overtube-assisted enteroscopy ERCP in patients with surgically altered pancreaticobiliary anatomy (with video). Gastrointest Endosc 2013; 77: 593-600

5 Wang AY, Sauer BG, Behm BW et al. Singleballoon enteroscopy effectively enables diagnostic and therapeutic retrograde cholangiography in patients with surgically altered anatomy. Gastrointest Endosc 2010; 71: 641-649

6 Saleem A, Baron TH, Gostout CJ et al. Endoscopic retrograde cholangiopancreatography using a single-balloon enteroscope in patients with altered Roux-en-Y anatomy. Endoscopy 2010; 42: 656-660

7 Matsushita M, Shimatani M, Ikeura T et al. Single-balloon or short double-balloon enteroscope for ERCP in patients with surgically altered anatomies. Gastrointest Endosc 2011; 73: 415-416; author reply 416-417

${ }^{1}$ Division of Gastroenterology, Department of Internal Medicine, Mackay Memorial Hospital, Taipei, Taiwan

2 Mackay Junior College of Medicine, Nursing and Management, Taipei, Taiwan

${ }^{3}$ Health Evaluation Center, Mackay Memorial Hospital, Taipei, Taiwan,

${ }^{4}$ Mackay Medical College, New Taipei, Taiwan,
Bibliography

Dol http://dx.doi.org/ 10.1055/s-0033-1344588

Endoscopy 2014; 46: E242-E243

(c) Georg Thieme Verlag KG

Stuttgart · New York

ISSN 0013-726X

Corresponding author Horng-Yuan Wang, MD Division of Gastroenterology Department of Internal Medicine Mackay Memorial Hospital No. 92, Sec. 2, Chung-Shan N. Road Taipei

Taiwan

Fax: +886-2-25433642

mmhgiman@gmail.com 